Springer Link Header: Transplant and Oncology (Michael Ison, Nicole Theodoropoulos and Steve Pergam, Section Editors)

\title{
Immune monitoring for CMV in transplantation
}

Michelle K. Yong ${ }^{1,2}$, Sharon R. Lewin ${ }^{1}$, Oriol Manuel ${ }^{3,4}$

${ }^{1}$ The Peter Doherty Institute for Infection and Immunity, The University of Melbourne and Royal Melbourne Hospital, Melbourne, Australia

${ }^{2}$ National Centre for Infections in Cancer, Peter MacCallum Cancer Centre, Melbourne, Australia

${ }^{3}$ Infectious Diseases Service, Department of Medicine, University Hospital and University of Lausanne, Lausanne, Switzerland

${ }^{4}$ Transplantation Center, Department of Anesthesiology and Surgery, University Hospital and University of Lausanne, Lausanne, Switzerland

Keywords: Cytomegalovirus, solid organ transplantation, stem cell transplantation,

CMV specific immunity, immune monitoring, Quantiferon-CMV, ELISPOT

Word count:

- Abstract: 174

- Main body: 3999

Corresponding author:

Michelle K. Yong

The Peter Doherty Institute for Infection and Immunity

The University of Melbourne and Royal Melbourne Hospital

792 Elizabeth Street

Melbourne VIC 3000

Email: Michelle.Yong@unimelb.edu.au

Conflict of interest declaration:

Dr. Manuel has received research grants from Lophius Biosciences $\mathrm{GmbH}$ and from Qiagen. Dr. Yong and Dr. Lewin declare no conflict of interest.

\section{Human and Animal Rights and Informed Consent}


This article does not contain any studies with human or animal subjects performed by any of the authors. 


\section{Abstract}

Purpose of Review Immune monitoring to determine when and how the recovery of cytomegalovirus (CMV) specific T-cells occurs post-transplantation may help clinicians to risk stratify individuals at risk of complications from CMV. We aimed to review all recent clinical studies using CMV immune monitoring in the pre- and posttransplant setting including the use of recently developed standardized assays (Quantiferon-CMV and the CMV-ELISPOT) to better understand in whom, when and how immune monitoring is best used.

Recent Findings Pre-transplant assessment of CMV immunity in solid organ transplant recipients where CMV seropositive recipients had undetectable cellmediated responses despite past immunity, are at a much higher risk of developing CMV reactivation. Post-transplant CMV immune monitoring can guide (shorten or prolong) the duration of antiviral prophylaxis, identify recipients at risk of postprophylaxis CMV disease and predict recurrent CMV reactivation.

Summary Thus CMV immune monitoring, in addition to current clinical and DNAbased monitoring for CMV, has the potential to be incorporated into routine clinical care to better improve CMV management in both the stem and solid organ transplant population. 


\section{Introduction}

Cytomegalovirus (CMV) has been one of the leading causes of infectious complications in transplant recipients in the last decades (1). However, significant improvements in the management of CMV infection have been accomplished over time. First, the advent of oral antiviral therapies, such as oral ganciclovir and valganciclovir, has allowed the routine implementation of universal preventive strategies, namely antiviral prophylaxis (i.e. the use of an antiviral drug early after transplant for a defined high-risk period of time) $(2,3)$ and the preemptive approach (i.e. the monitoring of CMV replication and administration of antiviral therapy only in those patients with CMV replication, to avoid progression to overt CMV disease and to prevent unecessary drug toxicity) (4). These strategies have greatly reduced the incidence and improved outcomes of CMV disease (5). Second, the use of molecular testing for the monitoring of CMV replication and the diagnosis of CMV disease has allowed a more accurate identification and an earlier diagnosis of CMV replication (6). Finally, despite the use of more potent immunosuppressive drugs in solid-organ transplantation, new regimens have reduced the rates of acute rejection and improved allograft function and survival, thus reducing the overall rates of opportunistic infections $(7,8)$.

There remain opportunities for improving the management of transplant patients with CMV infection. Patients at high risk for CMV disease, namely donor positive / recipient negative ( $\mathrm{D}+/ \mathrm{R}-)$ in solid-organ transplant (SOT) recipients and seropositive $(\mathrm{R}+)$ hematopoietic stem-cell transplant (HSCT) recipients may still develop clinically severe CMV disease, occasionally associated with antiviral drug resistance $(9,10)$. Despite the wide implementation of preventive strategies, studies have pointed out the potential association between CMV replication (particularly early after transplant, but potentially also after the discontinuation of prophylaxis) and 
impaired organ allograft outcomes even in the current era (5). Drug costs and toxicity remains a concern, particularly in HSCT recipients, thus fine-tuning of the use of antiviral drugs only in those patients who are actually on risk for developing CMVrelated complications is necessary (11).

Immune monitoring (i.e. the use of cell-mediated immune assays for assessing the hosts specific immune response to CMV) could be used to guide the optimal duration of prophylactic or pre-emptive anti-CMV treatment $(12,13)$. Until recently, the assays used to measure CMV immunity were labour and resource intensive. The development of rapid, high through-put CMV immune assays such as the Quantiferon-CMV or commercial CMV-ELISPOT assays has facilitated the ease of assessing immunity in clinical laboratories with rapid availability of results to both transplant and non-transplant physicians $(14,15)$. Thus, we wanted to evaluate all recent clinical studies which employed CMV immune monitoring in the pre- and posttransplant setting to understand the clinical utility of predicting CMV clinical events.

\section{CMV cell-mediated immune assays}

\section{Quantiferon-CMV® assay}

The Quantiferon-CMV® assay (Qiagen Ltd) is rapidly emerging as a clinically useful assay for monitoring CMV immunity $(16,17)$. It is an in-vitro diagnostic test which is simple, rapid with the ability to be processed with high throughput in most diagnostic laboratories (18). The assay uses HLA-restricted CMV epitopes to stimulate CD8+ T-cells and consists of three blood tubes containing one of CMV peptide antigens, a positive mitogen control of phytohemagglutinin (PHA) or a negative control (18). An enzyme linked immunosorbent assay (ELISA) technique is used to measure IFN-y levels for CMV antigen and the PHA positive control (19). Results are expressed as qualitative (reactive, non-reactive or indeterminate) or quantitative results (IFN- $\gamma$ 
$\mathrm{IU} / \mathrm{ml}),(18)$. Major advantages and disadvantages of this assay are summarized in Table 1.

As with all tests of cell-mediated immunity, the presence of functional T-cells are required to obtain a result and therefore it is not recommended that testing be performed in the pre-engraftment period following HSCT when recipients are lymphopenic. Questions have arisen regarding the interpretation of "indeterminate" results which can occur in up to $38 \%$ of post-transplant recipients (20). Although indeterminate can result from improper laboratory processing of the sample, many indeterminate results are due to inadequate T-cell responses to mitogen and thus is a reflection of an individual's low or dysfunctional T cells with results being highly correlated to the peripheral blood lymphocyte count $(20,21)$. Indeterminate results are therefore often observed during periods of profound immunosuppression, such as early transplantation or administration of systemic corticosteroids to manage acute rejection or graft versus host disease (GVHD) (21). In these populations, an indeterminate result can be quite informative and reflects the ongoing lowered net state of T-cell immunosuppression, meaning that the individual remains at high risk of subsequent CMV reactivation (15). Additionally, we found that a low T-cell response to mitogen is also predictive of 12 month mortality and non-relapse related mortality in the HSCT population (21).

\section{ELISPOT}

Enzyme linked immunosorbent spot assay (ELISPOT) is another commonly used technique to detect the presence of functional CMV specific T-cells by measuring the production of IFN-y or other cytokines in response to antigenic stimulation (22). It is a highly sensitive assay with the ability to assess functional cytokine release down to the single cell level (22). Recently, two standardized and commercially available 
ELISPOT assays have been developed; the T-Track® CMV ELISPOT assay (Lophius Biosciences GmbH, Regensburg, Germany) (23, 24) and the TSPOT.CMV® assay (Oxford Immunotec Ltd, UK) (25). Instead of using laboratory inhouse CMV peptides or proteins, the T-Track® CMV assay utilizes recombinant urea-formulated CMV pp65 and IE-1 stimulants which have the advantage of activating a broader range of effector cells (CD4+, CD8+ T-cells, NK and NK T cells) (24). These standardized ELISPOT assays will significantly improve comparison of results between laboratories and transplant centres; a factor which has been a major limitation with the ELISPOT technique in the past.

CMV ELISPOT requires the isolation of peripheral blood mononuclear cells (PBMCs) after which they are stimulated with CMV antigens before antibodies against IFN- $\mathrm{y}$ or other cytokines are used to detect the cytokine of interest. Drawbacks to the widespread use of CMV ELISPOT are limited accessibility and isolation of PBMCs remains resource intensive.

Intracellular cytokine staining (ICS) and flow cytometry Intracellular cytokine staining (ICS) techniques have the ability to simultaneously detect multiple cell surface markers and cytokines, allowing for an indepth evaluation of functional CMV-specific immunity. In addition, the source of cytokine production i.e. CD4+ or CD8+ T cells can be determined. Whole blood or PBMCs are stimulated with CMV peptides, following which the cells produce detectable levels of cytokines; IFN- $\gamma$, TNF- $\alpha$, and IL-2 for example. Fluoresceincoated antibodies are used to stain the intracellular cytokines of interest.

Although the ICS studies have the advantage to characterise in more depth the immune phenotypes and functional cytokine responses of CMV immunity, it is quite limiting as a bedside clinical tool and remains more of a research academic 
technique. In general, the assay lacks standardisation, is resource intensive, expensive to perform and the results can require expert interpretation. Colleagues at Duke University are currently addressing some of the limitations of the polyfunctional ICS technique and the future may bring a more standardized approach where results will be more easily compared (26).

\section{Tetramer binding}

Tetramers are major histocompatibility (MHC)-I-peptide based complexes used in the detection of antigen specific T-cells (27). Staining for tetramers enables rapid and direct visualization of CMV-specific immune cells allowing direct quantification of these cells (28). It can be performed on either whole blood or PBMCs and is used together with flow cytometry to identify specific immune phenotypes. Binding of the tetramer is HLA dependent, therefore knowledge of HLA typing is required in order to interpret the result (28). Other features of the tetramer binding may be important as investigators recently demonstrated that the degree of tetramer binding, being high or low avidity T-cells, differed by their proliferation capability, quantity and T-cell receptor repertoire (29).

\section{Clinical experience with immune monitoring for CMV in solid-organ transplant recipients}

There are several clinical scenarios where immune monitoring could be used in the routine practice in both SOT and HSCT recipients (Figure 1). This section will discuss on the studies performed in SOT recipients.

Pre transplant assessment

The CMV serostatus of the donor and the recipient at the time of transplant is the most informative test to stratify the risk for CMV infection in the post-transplant 
period and to establish the preferred antiviral preventive strategy. Most centers prefer to give antiviral prophylaxis in high-risk donor positive, recipient negative CMV serostatus (D+/R-) and manage the patients either with antiviral prophylaxis or with a preemptive approach in intermediate risk CMV seropositive patients $\left(R_{+}\right)(6)$.

Recent data suggest, however, that a better stratification can be achieved by using a cell-mediated immune assay in the pre-transplant period $(29,30)$. This is particularly true among those $\mathrm{R}+$ patients who actually have an undetectable cellmediated immune response. These patients behave post-transplant as immune naïve patients rather than as patients with preexistent immunity to CMV. Using a Quantiferon-CMV assay, Cantisan and colleagues investigated the correlation between pre-transplant serology and cell-mediated immunity in a cohort of 55 heart and kidney transplant recipients (30). While all seronegative patients had a negative Quantiferon-CMV assay, only two thirds of seropositive patients also had a detectable cell-mediated immunity against CMV. Those patients with discordant results (positive serology and negative cell-mediated immune assay) had a 10-fold increased risk for CMV replication post-transplant (30). In addition, the only patients who developed CMV disease were patients with a negative Quantiferon-CMV assay, irrespective of the serostatus of the donor and the recipient (30). These results were confirmed in a larger cohort of 137 kidney transplant recipients using an ELISPOTCMV (31). Patients with a low pre-transplant IE-1 response showed a higher risk for CMV replication and disease irrespective whether the patients received prophylactic or preemptive antivirals and whether they received induction therapy with lymphocyte-depleting antibodies (31). More recently, the same investigators have established a cut-off for both pp65 and IE-1 responses that accurately discriminates with high positive and negative predictive values between patients with or without 
risk for developing CMV replication post transplant (Abstract \#OS234, ESOT meeting 2017). Two additional studies found that a percentage of seronegative recipients may show preformed detectable cell-mediated immune responses to IE-1 and pp65 (probably due to seroreversion); these patients have lower risk for CMV replication than $\mathrm{D}+/ \mathrm{R}$ - patients with a negative cell-mediated immunity assay, independenly of the use of lymphocyte-depleting antibodies in the post transplant period $(32,33)$. A clinical trial assessing the benefit of an ELISPOT-CMV pretransplant has been recently completed (see point Future directions below).

\section{Assessment during prophylaxis}

Antiviral prophylaxis with oral agents is one of the most successful strategies to decrease the incidence and severity of CMV disease after transplantation (5). However, antiviral drugs are expensive and associated with some toxicity. An interesting approach would be to adapt the duration of antiviral drugs by dynamically assessing throughout the prophylaxis period the presence of detectable cellmediated immunity.

There are few data on the timeline for developing cell-mediated immunity in D+/R- patients receiving antiviral prophylaxis. In a multicenter cohort involving 95 D+/R- transplant recipient receiving 3 to 6 month antiviral prophylaxis, cell-mediated immunity was determined using intracellular cytokine staining at 1, 3, 4, 6 and 12 months post-transplant (34). Up to $20 \%$ to $50 \%$ of patients had a positive result between 3 to 6 months post-transplant, and this was associated with protection against the development of CMV disease, with very high positive predictive values (34). We also assessed CMV cell-mediated immunity with the Quantiferon-CMV assay in $127 \mathrm{D}+/$ R- patients at the end of 3 to 6 months of antiviral prophylaxis (16). Only $12 \%$ of patients had a positive assay at the time of discontinuing prophylaxis 
with this percentage increasing to $26 \%$ two months later. The Quantiferon-CMV assay showed a $93 \%$ positive predictive value for predicting protection against CMV disease. In this study, up to $75 \%$ of patients had a negative Quantiferon-CMV result, but only $26 \%$ of them eventually developed CMV disease(16). A recent randomized study of 118 lung transplant recipients demonstrated that monitoring CMV immunity from the end of 5 months prophylaxis could guide prophylaxis duration and reduced late onset CMV reactivation (35). Participants randomized to Quantiferon-CMV guided antiviral prophylaxis duration compared to standard of care (cease antivirals at 5 months) had significantly improved outcomes (35). These data indicate that patients with detectable cell-mediated immunity by the Quantiferon-CMV assay can safely discontinue antiviral prophylaxis with a low risk for developing CMV disease, but the assay is not sensitive enough to discriminate those patients with undetectable cell-mediated immunity who will eventually develop CMV related complications. Two clinical trials determining the duration of antiviral prophylaxis according to the results of a cell-mediated immune assay are ongoing.

Determination of the risk of relapse of CMV replication after antiviral therapy Rates of relapse of treated CMV disease may vary between $10 \%$ and $35 \%(5,36$, 37). In a clinical trial where 321 SOT recipients with CMV disease were randomized to receive oral valganciclovir or intravenous ganciclovir, rates of clinical and virological relapse were $15 \%$ and $30 \%$, respectively (36). In this study, the only clinical factor associated with clinical relapse was a detectable CMV replication at three weeks of antiviral therapy. Cell-mediated immunity would theoretically help to determine which patients might benefit for extended secondary antiviral prophylaxis with the aim to reduce the rates of relapsing CMV infection. 
үठ T-cells are a subtype of T-cells involved in the immune response to CMV, but not to other viruses such as influenza or EBV (38). The rapid and broad expansion of $\mathrm{\delta} \mathrm{T}$-cells in response to $\mathrm{CMV}$ replication have been associated with a better control of CMV after transplant. Kaminski and colleagues assessed the role of dynamics of $ү \delta \mathrm{T}$-cells in predicting the risk of relapse in high-risk patients including $168 \mathrm{D}+\mathrm{R}$ - patients and $104 \mathrm{R}+$ patients receiving thymoglobulin (39). In this study, үठ T cell expansion was associated with absence of relapse in $94.7 \%$ of cases. (39). Recently, an interventional uncontrolled trial used the Quantiferon-CMV assay to determine which recipients with CMV infection required ongoing secondary antiviral prophylaxis (40). Of the 27 patients enrolled, 14 had a detectable cell-mediated immune response at the end of antiviral therapy. These patients did not receive antiviral prophylaxis and only one patient had a virological relapse. In contrast, the 13 patients with an undetectable cell-mediated immune response, despite having received an antiviral drug for 2 months, up to $69 \%$ of them had virological or clinical relapse.

Immune monitoring during antiviral therapy has also been used in the context of drug-resistant CMV infection, to determine the indication for therapy with foscarnet or cidofovir in patients with relapsing DNAemia (41).

\section{Other clinical indications}

Cell-mediated immunity assays have also been used in determining whether patients with CMV replication during the preemptive management should receive antiviral therapy or not. Patients with CMV replication and a negative result of a cell-mediated immunity assay (either a Quantiferon-CMV assay (42) or by ICS (43)) had a higher risk to progress to high-level replication or to CMV disease, than patients with a detectable cell-mediated immunity. Cell-mediated immunity assays may replace or 
complement CMV PCR for improving the preemptive management of CMV replication.

\section{CMV immune monitoring in the HSCT population}

In contrast to the SOT population, the most frequent strategy for prevention of CMV disease in the at-risk HSCT population $\left(D_{+} / R_{+}, D_{-} / R_{+}, D_{+} / R_{-}\right)$is pre-emptive monitoring and early treatment upon detection of CMV infection, since prophylactic ganciclovir is unacceptably toxic (44-46). As such, CMV immune monitoring in HSCT recipients aims to risk stratify individuals undergoing pre-emptive therapy, most commonly in the early post-HSCT period ( $<100$ days) when the severity of immunosuppression is often profound. Importantly, the at-risk period of CMV complications is highly dependent on the clinical course of the transplantation; in particular, an increased risk of CMV complications occurs with the development of GVHD and subsequent further immunosuppression $(25,47)$.

CMV immune monitoring in conjunction with current pre-emptive strategies based on viral load detection has demonstrated important clinical utility $(15,25,48)$. Studies in the HSCT population have shown immune monitoring to predict early CMV reactivation (25), predict recurrent CMV reactivation $(15,22,28,48-50)$, shorten duration of anti-CMV pre-emptive therapy $(48,51)$, accurately reflect CMV viral load $(20,52)$, predict individuals most likely to clear infection spontaneously $(53)$ and an association with CMV end-organ disease $(15,19)$.

\section{Predict CMV reactivation}

Recently, a study of 63 HSCT recipients using T.SPOT.CMV® ELISPOT monitoring up to day 100 showed that individuals with high compared to low ELISPOT responses were protected against CMV reactivation (Kaplan Meier failure 
curves of time to CMV reactivation log rank test $p=0.009$ ) (25). Individuals who developed CMV reactivation despite adequate CMV immunity were those on systemic corticosteroids or had developed acute GVHD (25), similarly observed by other investigators $(48,51)$. Overall the study period was short (100 days) when clearly the risk of CMV complications extends beyond this time and a much longer follow up is required to assess the predictive value of CMV immune monitoring (25). The CMV ELISPOT assay performed well in the early post-HSCT period in this study demonstrating a sensitivity of $91 \%$ for CMV reactivation and a negative predictive value of $88 \%(25)$. These results contrast with other studies demonstrating much less accurate CMV immune results in the first 100 days, albeit using different assay techniques $(20,50)$.

In a multi-centre study of 94 HSCT recipients using the Quantiferon-CMV and CMV ELISPOT assay, we showed that an indeterminate Quantiferon-CMV result at 100 days had an $83 \%$ positive predictive value and $98 \%$ negative predictive value for identifying recurrent CMV reactivation (15). The Quantiferon-CMV assay also showed that of HSCT recipients with a reactive, indeterminate or negative CMV immune response, spontaneous viral clearance was observed in $49 \%, 10 \%$ and $0 \%$ of participants, respectively $(p<0.001)$ (15). Furthermore, participants with CMV disease had the lowest magnitude of IFN-y production compared to individuals with spontaneous viral control and CMV reactivation (15). In a smaller study of pediatric HSCT recipients using the Quantiferon-CMV assay, a negative or indeterminate result was associated with recurrent $\mathrm{CMV}$ infection whereas a reactive test was associated with no CMV recurrence, consistent with CMV immunity (49).

In the pediatric HSCT population, CMV ELISPOT monitoring showed that recipients who experienced $\mathrm{CMV}$ reactivation compared to those without $\mathrm{CMV}$ 
viremia had a significantly lower median ELISPOT level (22). An ELISPOT of $>80$ spots/200,000 PBMCs was considered to provide protective CMV immunity whereas an ELISPOT of $<20$ spots/200,000 PBMCs was a risk factor for subsequent CMV reactivation (22).

CMV immune monitoring using tetramer staining in 278 HSCT recipients demonstrated the development of one CMV-specific $T$ cell/ $\mu$ l between days $50-75$ post-HSCT (50). In the R+/D+ groups, this level of CMV immunity correlated well with no observable CMV reactivation and individuals with more frequent CMVspecific T cells had fewer recurrent CMV reactivations (50).

\section{Shorten duration of anti-CMV treatment}

Immune monitoring can also be used to individualise the duration of preemptive anti-CMV treatment as shown in a study where CMV treatment was stopped if detectable CMV immunity (defined as pp65/IE-1 specific IFN-ץ producing CD8+ T cell level of $>$ one cell $/ \mu$ l) was seen within 30 days after treatment initiation (48). Using ICS and flow cytometry, 11 of 61 HSCT recipients had their antiviral treatment interrupted with these participants receiving a significantly shorter duration of antiCMV treatment (22 versus 31 days, $\mathrm{p}=0.003$ ) and observed lower rates of recurrent CMV infection (48). These findings demonstrate how the addition of CMV immune monitoring to pre-emptive strategies can lead to a significant reduction in unnecessary anti-viral treatment, thus potentially avoiding drug toxicity to the HSCT recipients as well as reducing costs (48).

The development of CMV immunity shortly after the occurrence CMV reactivation has been associated with significantly lower CMV maximum viral loads as evaluated in a study of 41 HSCT recipients where Quantiferon-CMV monitoring was evaluated in the first 100 days post-HSCT (20). Individuals who developed CMV 
immunity in the week following CMV reactivation had a 6.5 fold lower peak CMV viral load than individuals who did not develop immunity (20). This study also showed that weekly CMV immune monitoring in the early period post-HSCT did not add any additional benefit or accuracy in predicting CMV events (20). In fact, 38\% of all tests performed were indeterminate and/or highly variable (20).

CMV immune monitoring studies using ICS and flow cytometry have the ability to not only predict CMV clinical outcomes $(48,53)$ but also provide a better understanding of the multi-functional cytokine responses of CMV-specific T cells and T cell subsets $(52,53)$. In pediatric HSCT, where treatment was not initiated until a CMV viral load of 30,000 DNA copies $/ \mathrm{ml}$ was reached, a CMV immune response of one CMV-specific CD4 ${ }^{+} \mathrm{T}$ cell and three CMV-specific $\mathrm{CD}^{+} \mathrm{T}$ cells $/ \mu \mathrm{l}$, accurately predicted CMV immune reconstitution, ability to spontaneously control CMV viremia and protection against CMV disease (53). Reduced proportions of multi-functional $\left(\mathrm{IFN}-\mathrm{\gamma}^{+} / \mathrm{TNF}-\alpha^{+}\right) \mathrm{CD}^{+}$and $\mathrm{CD}^{+} \mathrm{T}$ cells have been observed in HSCT recipients experiencing CMV reactivation compared to no reactivation (15) and mono-functional cells are not only abundant (54) but predict progression to CMV viremia (52).

\section{Future directions}

While there is a growing evidence of the potential clinical use of immune monitoring for $\mathrm{CMV}$, some open questions remain regarding the best use of these assays. More studies are needed looking at the predictive value of cell-mediated immune assays in particular populations at different CMV risk, such as patients receiving lymphocytedepleting antibodies vs. anti-IL2R antibodies, mTOR inhibitors vs. calcineurin inhibitors, or in patients receiving long-term steroids therapy. Also the ideal timing for perfoming the assays has to be better delineated: while a pre transplant assessement seems easy to implement, the repeted use of cell-mediated immune 
assays in the post transplant period can be more difficult to apply in the clinical setting. So studies determining the value of a single time point (e.g. at 3 or 6 months post transplant) vs. several time points (once a month vs. twice a month) in improving the management of patients are also needed. Finally, it is not yet known whether these assays will be used as a complement or a substitute of the currently used viral monitoring by nucleic acid testing.

More importantly, so far there is a lack of interventional studies addressing the benefit of these tests in improving patient management, with respect to the standard of care (10). Fortunately, there are a number of clinical trials either completed or ongoing, assessing different clinical scenarios of immune monitoring.

First, a randomized controlled trial is evaluating the performance of a commercial ELISPOT-CMV assay (24) for determining the duration of antiviral prophylaxis in high-risk patients (NCT02538172). SOT recipients are randomized to receive either a fixed duration of antiviral prophylaxis (control arm) or an immune monitoring arm where antiviral prophylaxis is stopped when the ELISPOT-CMV is positive. Second, a single-arm multicenter trial is assessing the usefulness of the Quantiferon-CMV assay in determining the duration of prophylaxis in high-risk patients (NCT02784756). Finally, a randomized controlled trial is stratifying patients according to the results of a pre transplant ELISPOT-CMV (NCT02550639).

Further interventional studies of CMV immune monitoring are required in the HSCT population to determine whether pre-emptive antivirals can be safely stopped upon detection of CMV immunity (48). With the recent approval of the anti-CMV drug letermovir for primary prophylaxis in HSCT recipients (55), we will see a renewed interest in using universal primary prophylaxis in this population. Thus an evaluation of CMV immune monitoring to guide duration of letermovir prophylaxis would be of 
high clinical interest, particularly given the high costs associated with the use of letermovir. Furthermore studies using CMV immune monitoring in established CMV disease to determine secondary prophylaxis have yet to be performed in the HSCT population.

\section{Conclusions}

The use of CMV immune monitoring in the solid and stem cell transplant population to better identify individuals at greatest risk of CMV-related complications continues to be an area of high clinical need and interest. The development of high throughput, standardized assays of CMV immunity such as the Quantiferon-CMV and ELISPOTCMV will hopefully facilitate the incorporation of CMV immune monitoring into routine clinical care thus bringing us a step closer to the future of personalized medical care. 
Table 1: Advantages and disadvantages of the techniques used to measure CMV cell-mediated immune responses

\begin{tabular}{|c|c|c|c|c|c|c|}
\hline $\begin{array}{l}\text { Immune } \\
\text { Assay }\end{array}$ & Technique & $\begin{array}{c}\text { PBMC } \\
\text { Requirement }\end{array}$ & Cost & $\begin{array}{l}\text { Technical } \\
\text { difficulty }\end{array}$ & Advantages & Disadvantages \\
\hline $\begin{array}{l}\text { ELISPOT } \\
\text { T-Track }^{\circledR} \text { CMV } \\
\text { T-SPOT.CMV }\end{array}$ & $\begin{array}{l}\text { PBMCs are stimulated with } \\
\text { CMV overlapping peptides } \\
\text { and positive mitogen. } \\
\text { Measures IFN-y and output } \\
\text { is expressed as SFC/cells }\end{array}$ & Yes & ++ & ++ & $\begin{array}{l}\text { Highly sensitive } \\
\text { New commercially } \\
\text { available ELISPOT } \\
\text { assays are } \\
\text { standardized }\end{array}$ & $\begin{array}{l}\text { Requires PBMC } \\
\text { isolation } \\
\text { Lack of defined cut- } \\
\text { offs for positivity } \\
\text { Lack of } \\
\text { standardisation using } \\
\text { in-house ELISPOT } \\
\text { methods }\end{array}$ \\
\hline $\begin{array}{l}\text { Intracellular } \\
\text { cytokine } \\
\text { staining }\end{array}$ & $\begin{array}{l}\text { Whole blood or PBMCs are } \\
\text { stimulated with CMV } \\
\text { peptides and stained with } \\
\text { fluorochrome antibodies to } \\
\text { detect numerous intra- } \\
\text { cytoplasmic cytokines }\end{array}$ & Yes and No & +++ & +++ & $\begin{array}{l}\text { Ability to detect } \\
\text { multiple cytokines and } \\
\text { cell surface markers } \\
\text { Can differentiate T cell } \\
\text { phenotypes }\end{array}$ & $\begin{array}{l}\text { Specialised flow } \\
\text { cytometer equipment } \\
\text { required } \\
\text { Lack of } \\
\text { standardisation } \\
\text { Expensive }\end{array}$ \\
\hline $\begin{array}{l}\text { Tetramer } \\
\text { Staining }\end{array}$ & $\begin{array}{l}\text { These dye labelled } \\
\text { tetramers bind to CMV }\end{array}$ & No & ++ & ++ & $\begin{array}{l}\text { Allows direct } \\
\text { visualisation and }\end{array}$ & HLA-restricted \\
\hline
\end{tabular}




\begin{tabular}{|l|l|l|l|l|l|}
\hline & $\begin{array}{l}\text { specific CD8+ T cells thus } \\
\text { helping to directly identify } \\
\text { and quantify the presence } \\
\text { of these cells. }\end{array}$ & & & quantification of cells & \\
\hline
\end{tabular}

ELISPOT; enzyme-linked immunosorbent spot assay, PBMC; peripheral blood mononuclear cells, CMV; cytomegalovirus, IFN-ү; interferon-gamma, SFC; spot forming colony, ELISA; enzyme linked immunosorbent assay, HLA; human leukocyte antigen 
Figure 1. Potential clinical scenarios for the use of CMV specific cell-mediated immune assays on the management of CMV infection in solid-organ and stemcell transplant recipients.

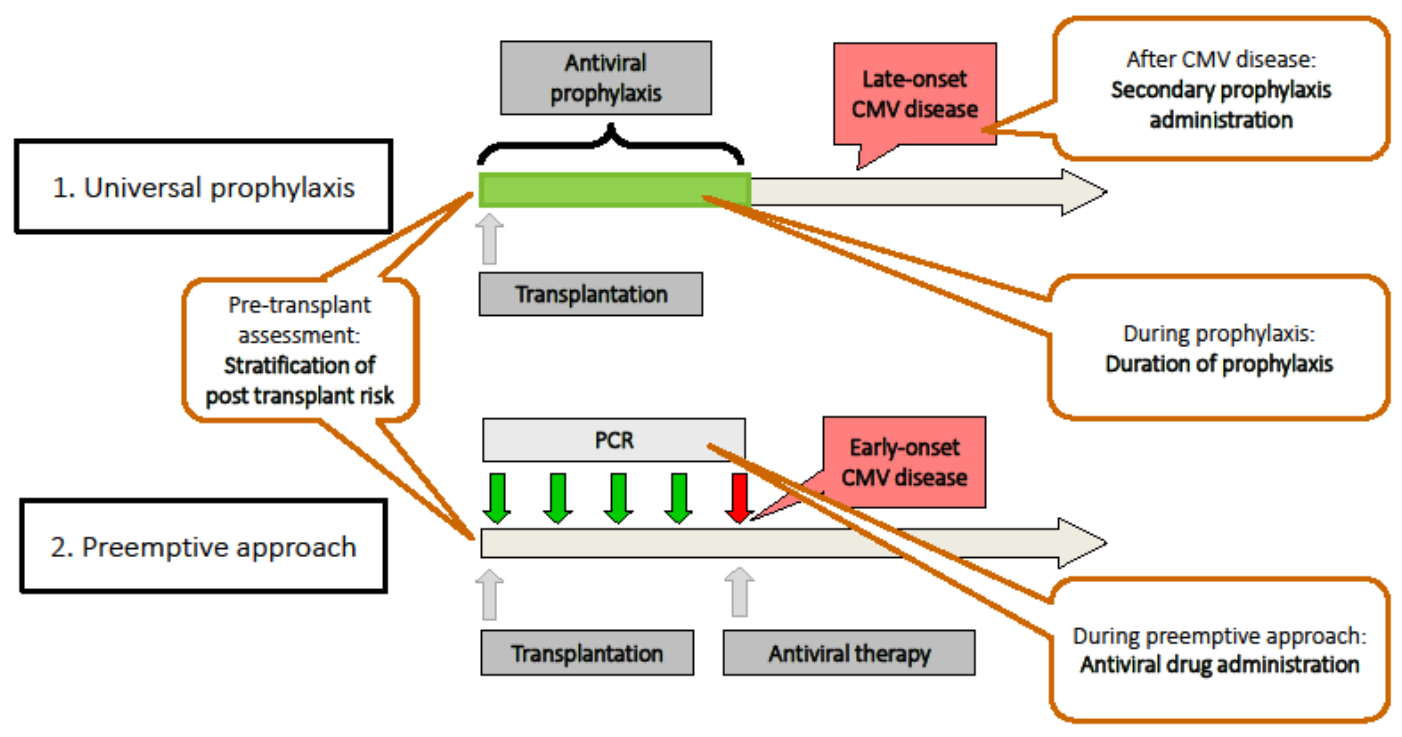




\section{References}

Papers of particular interest, published recently, have been highlighted as:

* Of importance

${ }^{* *}$ Of major importance

1. Razonable RR, Humar A, Practice ASTIDCo. Cytomegalovirus in solid organ transplantation. American journal of transplantation : official journal of the American Society of Transplantation and the American Society of Transplant Surgeons. 2013;13 Suppl 4:93-106.

2. Humar A, Lebranchu Y, Vincenti F, Blumberg EA, Punch JD, Limaye AP, et al. The efficacy and safety of 200 days valganciclovir cytomegalovirus prophylaxis in high-risk kidney transplant recipients. American journal of transplantation : official journal of the American Society of Transplantation and the American Society of Transplant Surgeons. 2010;10(5):1228-37.

3. Paya C, Humar A, Dominguez E, Washburn K, Blumberg E, Alexander B, et al. Efficacy and safety of valganciclovir vs. oral ganciclovir for prevention of cytomegalovirus disease in solid organ transplant recipients. American journal of transplantation : official journal of the American Society of Transplantation and the American Society of Transplant Surgeons. 2004;4(4):611-20.

4. Matter-Walstra KW, Greiner M, Cusini A, Schiesser M, Ledergerber B, Fehr T, et al. Stringent adherence to a cytomegalovirus-prevention protocol is associated with reduced overall costs in the first 6 months after kidney transplantation. Transpl Infect Dis. 2015;17(3):342-9.

5. Manuel O, Kralidis G, Mueller NJ, Hirsch HH, Garzoni C, van Delden C, et al. Impact of antiviral preventive strategies on the incidence and outcomes of cytomegalovirus disease in solid organ transplant recipients. American journal of transplantation : official journal of the American Society of Transplantation and the American Society of Transplant Surgeons. 2013;13(9):2402-10.

6. Navarro D, San-Juan R, Manuel O, Gimenez E, Fernandez-Ruiz M, Hirsch HH, et al. Cytomegalovirus infection management in solid organ transplant recipients across European centers in the time of molecular diagnostics: An ESGICH survey. Transpl Infect Dis. 2017.

7. Brennan DC, Daller JA, Lake KD, Cibrik D, Del Castillo D, Thymoglobulin Induction Study G. Rabbit antithymocyte globulin versus basiliximab in renal transplantation. $\mathrm{N}$ Engl $\mathrm{J}$ Med. 2006;355(19):1967-77.

8. Ekberg H, Tedesco-Silva H, Demirbas A, Vitko S, Nashan B, Gurkan A, et al. Reduced exposure to calcineurin inhibitors in renal transplantation. N Engl J Med. 2007;357(25):2562-75.

9. Boeckh $M$, Ljungman $\mathrm{P}$. How we treat cytomegalovirus in hematopoietic cell transplant recipients. Blood. 2009;113(23):5711-9.

10. Kotton CN, Kumar D, Caliendo AM, Asberg A, Chou S, Danziger-Isakov L, et al. Updated international consensus guidelines on the management of cytomegalovirus in solid-organ transplantation. Transplantation. 2013;96(4):333-60.

11. Martin-Gandul C, Perez-Romero P, Gonzalez-Roncero FM, Berdaguer S, Gomez MA, Lage $E$, et al. Clinical impact of neutropenia related with the preemptive therapy of CMV infection in solid organ transplant recipients. J Infect. 2014;69(5):500-6.

12. Manuel O. Clinical Experience with Immune Monitoring for Cytomegalovirus in Solid-Organ Transplant Recipients. Curr Infect Dis Rep. 2013.

13. Kotton CN. Cytomegalovirus immunodiagnostics: Getting closer to personalized cytomegalovirus prevention? Liver Transpl. 2015;21(12):1462-4.

14. Sester M, Leboeuf C, Schmidt T, Hirsch HH. The "ABC" of Virus-Specific T Cell Immunity in Solid Organ Transplantation. American journal of transplantation : official journal of the American Society of Transplantation and the American Society of Transplant Surgeons. 2016;16(6):1697-706.

15. Yong MK, Cameron PU, Slavin M, Morrissey CO, Bergin K, Spencer A, et al. Identifying Cytomegalovirus Complications Using the Quantiferon-CMV Assay After Allogeneic Hematopoietic Stem Cell Transplantation. The Journal of infectious diseases. 2017;215(11):1684-94.

16. Manuel O, Husain S, Kumar D, Zayas C, Mawhorter S, Levi ME, et al. Assessment of cytomegalovirus-specific cell-mediated immunity for the prediction of cytomegalovirus disease in highrisk solid-organ transplant recipients: a multicenter cohort study. Clinical infectious diseases : an official publication of the Infectious Diseases Society of America. 2013;56(6):817-24. 
17. Giulieri S, Manuel O. QuantiFERON(R)-CMV assay for the assessment of cytomegalovirus cell-mediated immunity. Expert Rev Mol Diagn. 2011;11(1):17-25.

18. Walker S, Fazou C, Crough T, Holdsworth R, Kiely P, Veale M, et al. Ex vivo monitoring of human cytomegalovirus-specific CD8+ T-cell responses using QuantiFERON-CMV. Transpl Infect Dis. 2007;9(2):165-70.

19. Avetisyan G, Aschan J, Hagglund H, Ringden O, Ljungman P. Evaluation of intervention strategy based on CMV-specific immune responses after allogeneic SCT. Bone Marrow Transplant. 2007;40(9):865-9.

20. Tey SK, Kennedy GA, Cromer D, Davenport MP, Walker S, Jones LI, et al. Clinical assessment of anti-viral CD8+ T cell immune monitoring using QuantiFERON-CMV $(R)$ assay to identify high risk allogeneic hematopoietic stem cell transplant patients with CMV infection complications. PLoS One. 2013;8(10):e74744.

21. Yong MK, Cameron PU, Slavin MA, Cheng AC, Morrissey CO, Bergin K, et al. Low T-Cell Responses to Mitogen Stimulation Predicts Poor Survival in Recipients of Allogeneic Hematopoietic Stem Cell Transplantation. Frontiers in immunology. 2017;8:1506.

22. Abate D, Saldan A, Mengoli C, Fiscon M, Silvestre C, Fallico L, et al. Comparison of cytomegalovirus (CMV) enzyme-linked immunosorbent spot and CMV quantiferon gamma interferonreleasing assays in assessing risk of CMV infection in kidney transplant recipients. J Clin Microbiol. 2013;51(8):2501-7.

23. Banas B, Boger CA, Luckhoff G, Kruger B, Barabas S, Batzilla J, et al. Validation of T$\operatorname{Track}(\mathrm{R}) \mathrm{CMV}$ to assess the functionality of cytomegalovirus-reactive cell-mediated immunity in hemodialysis patients. BMC immunology. 2017;18(1):15.

24. Barabas S, Spindler T, Kiener R, Tonar C, Lugner T, Batzilla J, et al. An optimized IFNgamma ELISpot assay for the sensitive and standardized monitoring of CMV protein-reactive effector cells of cell-mediated immunity. BMC immunology. 2017;18(1):14.

25. Nesher L, Shah DP, Ariza-Heredia EJ, Azzi JM, Siddiqui HK, Ghantoji SS, et al. Utility of the Enzyme-Linked Immunospot Interferon-gamma-Release Assay to Predict the Risk of Cytomegalovirus Infection in Hematopoietic Cell Transplant Recipients. The Journal of infectious diseases. 2016;213(11):1701-7.

26. Staats JS, Enzor JH, Sanchez AM, Rountree W, Chan C, Jaimes M, et al. Toward development of a comprehensive external quality assurance program for polyfunctional intracellular cytokine staining assays. Journal of immunological methods. 2014;409:44-53.

27. Borchers S, Ogonek J, Varanasi PR, Tischer S, Bremm M, Eiz-Vesper B, et al. Multimer monitoring of CMV-specific T cells in research and in clinical applications. Diagn Microbiol Infect Dis. 2014;78(3):201-12.

28. Borchers S, Luther S, Lips U, Hahn N, Kontsendorn J, Stadler M, et al. Tetramer monitoring to assess risk factors for recurrent cytomegalovirus reactivation and reconstitution of antiviral immunity post allogeneic hematopoietic stem cell transplantation. Transpl Infect Dis. 2011;13(3):22236.

29. Ogonek J, Verma K, Schultze-Florey C, Varanasi P, Luther S, Schweier P, et al. Characterization of High-Avidity Cytomegalovirus-Specific T Cells with Differential Tetramer Binding Coappearing after Allogeneic Stem Cell Transplantation. Journal of immunology. 2017;199(2):792805.

30. Cantisan S, Lara R, Montejo M, Redel J, Rodriguez-Benot A, Gutierrez-Aroca J, et al. Pretransplant interferon-gamma secretion by CMV-specific CD8+ T cells informs the risk of CMV replication after transplantation. American journal of transplantation : official journal of the American Society of Transplantation and the American Society of Transplant Surgeons. 2013;13(3):738-45.

31. Bestard O, Lucia M, Crespo E, Van Liempt B, Palacio D, Melilli E, et al. Pretransplant immediately early-1-specific $T$ cell responses provide protection for CMV infection after kidney transplantation. American journal of transplantation : official journal of the American Society of Transplantation and the American Society of Transplant Surgeons. 2013;13(7):1793-805.

32. Lucia M, Crespo E, Melilli E, Cruzado JM, Luque S, Llaudo I, et al. Preformed frequencies of cytomegalovirus (CMV)-specific memory $\mathrm{T}$ and $\mathrm{B}$ cells identify protected CMV-sensitized individuals among seronegative kidney transplant recipients. Clinical infectious diseases : an official publication of the Infectious Diseases Society of America. 2014;59(11):1537-45.

33. Schachtner T, Stein M, Reinke P. CMV-Specific T Cell Monitoring Offers Superior Risk Stratification of CMV-Seronegative Kidney Transplant Recipients of a CMV-Seropositive Donor. Transplantation. 2017;101(10):e315-e25. 
34. San-Juan R, Navarro D, Garcia-Reyne A, Montejo M, Munoz P, Carratala J, et al. Effect of long-term prophylaxis in the development of cytomegalovirus-specific T-cell immunity in D+/R-solid organ transplant recipients. Transpl Infect Dis. 2015;17(5):637-46.

35. Westall GP, Cristiano Y, Peleg AY, Paraskeva M, Levvey B, Whitford H, et al. A study of QuantiFERON-CMV-directed CMV prophylaxis versus Standard-of-Care to Reduce Late CMV Reactivation in Patients undergoing Lung Transplantation. 37th International Society for Heart and Lung Transplantation Annual Meeting; San Diego, California 2017.

36. Asberg A, Humar A, Jardine AG, Rollag $\mathrm{H}$, Pescovitz MD, Mouas $\mathrm{H}$, et al. Long-term outcomes of CMV disease treatment with valganciclovir versus IV ganciclovir in solid organ transplant recipients. American journal of transplantation : official journal of the American Society of Transplantation and the American Society of Transplant Surgeons. 2009;9(5):1205-13.

37. Muheim C, Vogel G, Seydoux C, Gillet M, Mosimann F, Von Segesser L, et al. Determinants of protracted cytomegalovirus infection in solid-organ transplant patients. Transplantation. 2002;74(2):226-36.

38. Couzi L, Pitard V, Moreau JF, Merville P, Dechanet-Merville J. Direct and Indirect Effects of Cytomegalovirus-Induced gammadelta T Cells after Kidney Transplantation. Frontiers in immunology. 2015;6:3.

39. Kaminski H, Garrigue I, Couzi L, Taton B, Bachelet T, Moreau JF, et al. Surveillance of gammadelta T Cells Predicts Cytomegalovirus Infection Resolution in Kidney Transplants. J Am Soc Nephrol. 2016;27(2):637-45.

40. Kumar D, Mian M, Singer L, Humar A. An Interventional Study Using Cell-Mediated Immunity to Personalize Therapy for Cytomegalovirus Infection After Transplantation. American journal of transplantation : official journal of the American Society of Transplantation and the American Society of Transplant Surgeons. 2017;17(9):2468-73.

41. Mihm J, Leyking S, Dirks J, Smola S, Fliser D, Sester U, et al. Immune-based guidance of foscarnet treatment duration in a transplant recipient with ganciclovir-resistant cytomegalovirus infection. J Clin Virol. 2016;82:5-8.

42. Lisboa LF, Kumar D, Wilson LE, Humar A. Clinical utility of cytomegalovirus cell-mediated immunity in transplant recipients with cytomegalovirus viremia. Transplantation. 2012;93(2):195-200.

43. Mena-Romo JD, Perez Romero P, Martin-Gandul C, Gentil MA, Suarez-Artacho G, Lage E, et al. CMV-specific T-cell immunity in solid organ transplant recipients at low risk of CMV infection. Chronology and applicability in preemptive therapy. J Infect. 2017;75(4):336-45.

44. Boeckh $\mathrm{M}$, Ljungman $\mathrm{P}$. How we treat cytomegalovirus in hematopoietic cell transplant recipients. Blood. 2009;113(23):5711-9.

45. Thursky K, Byrnes G, Grigg A, Szer J, Slavin M. Risk factors for post-engraftment invasive aspergillosis in allogeneic stem cell transplantation. Bone Marrow Transplant. 2004;34(2):115-21.

46. Goodrich JM, Bowden RA, Fisher L, Keller C, Schoch G, Meyers JD. Ganciclovir Prophylaxis to Prevent Cytomegalovirus Diseases after Allogeneic Marrow Transplant. Ann Intern Med. 1993;118(3):173-8.

47. George B, Kerridge IH, Gilroy N, Huang G, Hertzberg MS, Bradstock KF, et al. A risk score for early cytomegalovirus reactivation after allogeneic stem cell transplantation identifies low-, intermediate-, and high-risk groups: reactivation risk is increased by graft-versus-host disease only in the intermediate-risk group. Transpl Infect Dis. 2012;14(2):141-8.

48. Navarro D, Amat P, de la Camara R, Lopez J, Vazquez L, Serrano D, et al. Efficacy and Safety of a Preemptive Antiviral Therapy Strategy Based on Combined Virological and Immunological Monitoring for Active Cytomegalovirus Infection in Allogeneic Stem Cell Transplant Recipients. Open Forum Infect Dis. 2016;3(2):ofw107.

49. Lee SM, Kim YJ, Yoo KH, Sung KW, Koo HH, Kang ES. Clinical Usefulness of Monitoring Cytomegalovirus-Specific Immunity by Quantiferon-CMV in Pediatric Allogeneic Hematopoietic Stem Cell Transplantation Recipients. Ann Lab Med. 2017;37(3):277-81.

50. Borchers S, Bremm M, Lehrnbecher T, Dammann E, Pabst B, Wolk B, et al. Sequential anticytomegalovirus response monitoring may allow prediction of cytomegalovirus reactivation after allogeneic stem cell transplantation. PLoS One. 2012;7(12):e50248.

51. Solano C, Benet I, Remigia MJ, de la Camara R, Munoz-Cobo B, Costa E, et al. Immunological monitoring for guidance of preemptive antiviral therapy for active cytomegalovirus infection in allogeneic stem-cell transplant recipients: a pilot experience. Transplantation. $2011 ; 92(4): \mathrm{e} 17-20$.

52. Hoegh-Petersen M, Roa L, Liu Y, Zhou F, Ugarte-Torres A, Louie $P$, et al. Low cytomegalovirus-specific T-cell counts at reactivation are associated with progression to high-level 
viremia or disease in seropositive recipients of hematopoietic cell grafts from seropositive but not seronegative donors. Cytotherapy. 2012;14(2):194-204.

53. Lilleri D, Gerna G, Zelini P, Chiesa A, Rognoni V, Mastronuzzi A, et al. Monitoring of human cytomegalovirus and virus-specific T-cell response in young patients receiving allogeneic hematopoietic stem cell transplantation. PLoS One. 2012;7(7):e41648.

54. Krol L, Stuchly J, Hubacek P, Keslova P, Sedlacek P, Stary J, et al. Signature profiles of CMV-specific T-cells in patients with CMV reactivation after hematopoietic SCT. Bone Marrow Transplant. 2011;46(8):1089-98.

55. Marty FM, Ljungman P, Chemaly RF, Maertens J, Dadwal SS, Duarte RF, et al. Letermovir Prophylaxis for Cytomegalovirus in Hematopoietic-Cell Transplantation. N Engl J Med. 2017. 


\section{University Library}

\section{- M M I E E R VA A gateway to Melbourne's research publications}

Minerva Access is the Institutional Repository of The University of Melbourne

Author/s:

Yong, MK;Lewin, SR;Manuel, O

Title:

Immune Monitoring for CMV in Transplantation

Date:

2018-04-01

Citation:

Yong, M. K., Lewin, S. R. \& Manuel, O. (2018). Immune Monitoring for CMV in Transplantation. CURRENT INFECTIOUS DISEASE REPORTS, 20 (4), https:// doi.org/10.1007/s11908-018-0610-4.

Persistent Link:

http://hdl.handle.net/11343/282984 